\title{
Loneliness and Cognitive Distortion in Adolescent Facebookers
}

\author{
Rani Agias Fitri and Syerlie July Anggita \\ SCC Clinical \& Developmental Psychology \\ Psychology Department Faculty of Humanities \\ BINUS University
}

\begin{abstract}
Facebook users in Indonesia dominated by adolescents in the age range 12 - 15 years. The usage of Facebook has negative effects, such as loneliness and cognitive distortion. The study aims to determine the relationship between loneliness and cognitive distortions in early adolescence Facebook users. Using revision of UCLA Loneliness Scale (ULS) - 8 (Hays \& DiMatteo, 1987) and Briere's (2000) Cognitive Distortion Scale (CDS), data was collected from 146 early adolescents, female and male, who studied at schools in East Jakarta, South Jakarta, North Jakarta, and Depok. Based on results of data analysis using Spearman Rank correlation. a significant positive correlation was obtained between loneliness and cognitive distortion on early adolescence Facebook users $(r=.271, p<.005)$. It was supported by a significant positive correlation between dimension of cognitive distortion (self criticism, self blame, helplessness, hopelessness, and preoccupation with danger) and loneliness with correlation rate $.234-.308$.
\end{abstract}

Keywords: loneliness, cognitive distortion, early adolescence, Facebook

Pengguna Facebook di Indonesia didominasi oleh remaja dari kelompok umur 12-15 tahun. Penggunaan Facebook menimbulkan dampak negatif, seperti kesepian dan distorsi kognitif. Studi ini bertujuan mengetahui hubungan antara kesepian dan distorsi kognitif pada remaja awal pengguna Facebook. Dengan menggunakan revisi USL-8 dan Cognitive Distortion Scale, dilakukan pengumpulan data pada 146 remaja awal berusia 12-15 tahun, baik laki-laki maupun perempuan, yang sekolahnya berada di Jakarta Timur, Jakarta Selatan, Jakarta Utara, dan Depok. Berdasarkan hasil pengolahan data menggunakan analisis korelasi Spearman Rank diperoleh hasil adanya hubungan positif yang signifikan antara kesepian dan distorsi kognitif pada remaja awal pengguna Facebook $(r=.271, p<.005)$. Hal ini didukung korelasi positif yang signifikan antara dimensi distorsi kognitif (self criticism, self blame, helplessness, hopelessness, dan preoccupation with danger) dan kesepian dengan rentang tingkat hubungan sebesar $.234-.308$.

Kata kunci: kesepian, distorsi kognitif, remaja awal, Facebook

Internet usage in the last decade has experienced a very rapid growth, including the use of social networking sites such as Facebook. In its growth, Facebook has become a rapidly developing social net-work site that is used very often (Doqruer, Menevis, \& Eyyam, 2011, Omolayo, Balogun, \& Omole, 2013, Kok, Lee, $\&$ Chong, 2015). In Indonesia, Facebook users are mostly aged 12-15 years old (Zuckerberg, Si Pembuat Facebook, 2009). This is supported by a survey done by the author in March 2014 on 12-15 year old teenagers, where it was found that Facebook was the most used

Correspondence concerning this article should be addressed to Rani Agias Fitri, SCC Clinical \& Developmental Psychology. Psychology Department Faculty of Humanities, BINUS University. Jl. Kemanggisan Ilir III No 45, Kemanggisan/Palmerah, Jakarta 11480. E-mail: h_ranny_k@yahoo.com social networking site.

Facebook enables its users to create a profile and share private information, pictures, videos, comments, and communicating with friends on Facebook through applications such as messages, gifts, groups, games, and fan pages (Aydin, Muyan, \& Demir, 2013). Facebook activities can be categorized into four main types: Internet interaction, spying/stalking, selfpresentation, and gaming (Yang \& Brown, 2013; Rosa $\&$ Santos, 2014). Among the four activites, the most frequent one is electronic interaction with friends, such as posting, commenting, or replying to messages. These are done to create a response from others or their own response towards other people's activity in Facebook. This indicates that Facebook is able to fulfil 
some basic human needs, such as the need to be connected and to share with friends (Kok, Lee, \& Chong, 2015).

However, the need to connect and share with friends using Facebook cannot be completely fulfilled. When someone is unable to express him/herself and consequently receive little information from others, he/she will feel dissatisfied and may experience loneliness (Leung, 2002). This could happen when, while using Facebook, teens feel embarassed to make a status or a comment, and so they do not get any feedback from their Facebook friends.

Loneliness can also occur when teens lose face-toface communication time with friends due to the amount of time spent on Facebook. It is very possible that teens may create new friendships using social networks, but such virtual relationship may weaken social and family relationships. Social networking sites also consume their time to do other activites, such as doing daily tasks and participating in social programs (Naeemi, Tamam, Hassan, \& Bolong, 2014).

Higher Internet usage is linked with significant reduction in social involvement, and increase in loneliness and depression (Lee \& Stapinski, 2013). Internet increases loneliness levels because users took time that can be used in social activities, and this increases social isolation (Seepersad, 2004), therefore reducing direct interaction between teenagers. Social networks push people to be closer to virtual machines, consequently pushing them apart from other people. This could explain why some people still feel lonely despite being surrounded by hundreds of online friends (Lee \& Stapinski, 2013).

Loneliness is explained as a negative feeling that arises when there's a gap between the real and the expected interpersonal affection and intimacy ( $\mathrm{Al}$ Khatib, 2012). Loneliness occurs when a person's connection is decreased qualitatively and quantitatively (Peplau \& Perlman, 1981). It can be concluded that loneliness is a subjective, negative experience resulting from the cognitive evaluation regarding the fit between quantity and quality of present relationship and the current relationship standard (Gierveld, Tilburg, $\&$ Dykstra, 2006). When experiencing loneliness, one will feel empty, sad, or longing (Al Khatib, 2012).

The use of Facebook may not only cause loneliness, but also cognitive distortion. Cognitive distortion has a central role in problematic Internet use (HuanHuan, \& $\mathrm{Su}, 2013)$. Cognitive distortion is excessive irrational, illogical and maladaptive thoughts (Nyarko, \& Amissah, 2014). Cognitive distortion is seen as a tendency to interpret or distort the meaning of events in ways that are consistent with negative self views, environment, and the future. Cognitive distortion is explained as systematic thinking errors, which include arbitrary inference, selective abstraction, overgeneralization, personalization, magnification, minimization, and dichotomous thinking (Wedding, 2000). Some examples include such as "no one understands me other than my chatting partner, "bad things always happen in my social life", "if i'm not popular, I'm a failure", or "I'm no one if I have no friends".

Cognitive distortion can occur on teenage Facebook users, because excessive Facebook use can create thinking errors related with the use of Facebook. Specific thinking errors will be related with interpretations regarding internet use (HuanHuan \& Su, 2013). Some thinking errors can be in the form of rumination, when teenagers are always focused on Facebook and not other events in their daily life. Negative self appraisal can occur when teenagers have negative self evaluations, motivating them to use Facebook to obtain positive responses from others, whereas all or nothing thinking is a form of thinking error that makes teenagers feel worthless without Facebook, or that no one loves them when they are offline.

From the explanations provided, it can be seen that Facebook use can bring about negative consequences. The use of Internet and technology has reached a level that has a negative impact on social relationships, most often related to Internet addiction (Oguz \& Cakir, 2014). Numerous studies have been done on Facebook addiction (Kuss, \& Griffiths, 2011, Dhaha, 2013; Zaremohzzabieh, Samah, Omar, Bolong, Kamarudin, 2014). In the current study, the relationship between social connections and Facebook addiction is examined through the variables loneliness and cognitive distortion. The author assumed that there is a significant positive relationship between loneliness and cognitive distortion on teenage users of Facebook. It is hoped that through this study, one can understand the presence or absence of a relationship between loneliness and cognitive distortion related with Facebook usage. If a relationship between loneliness and cognitive distortion is found, the significance of the relationship between loneliness and other dimensions of cognitive distortion can be investigated.

\section{Method}

\section{Participant and Procedure}

Subjects in this study were teenagers aged 12-15 years who are currently studying in the Jabodetabek 
area and are active users of Facebook, at least one hour per day. The minimum criterion of one hour of Facebook is considered enough (not too much and not too little) to utilize the various applications in Facebook. With a minimum usage time of one hour, it is assumed that subjects will have experienced the positive or negative impacts of Facebook.

Loneliness is not a criteria that needs to be possessed by the subjects due to the exploratory nature of the study, which was conducted to investigate the relationship between loneliness and cognitive distortion, without specificially looking at what level of loneliness that correlate with cognitive distortion.

Questionnaires were distributed from June $20^{\text {th }}$ to the $22^{\text {nd }}, 2014$, in a secondary school in Jakarta during a youth gathering activity. For practical reasons, age is the only criteria used during data collection, whereas Facebook activity was only known after subjects filled out control data in the questionnaire.

From 200 teenagers, data gathered were further refined by Facebook activity. In the end, 146 subjects were used in the study (12-13 years old: 76 people, 14-15 years old: 70 people; female: 88 and male: 58 ). Subjects went to school in North Jakarta, East Jakarta, South Jakarta, and Depok. Subjects' duration of Facebook use were as follows: $37 \%$ used it for 1-2 hours, $28.1 \%$ used it for 1 hour, $25.3 \%$ used it for 2-3 hours, and $9.6 \%$ used it for more than three hours. Three of the most frequently done activities in Facebook is updating status (2\%), uploading pictures and playing games $(17.3 \%)$ and updating status and uploading pictures $(16.9 \%)$.

\section{Measurement}

Loneliness was measured using UCLA Loneliness scale version 3 . Originally, this scale had 20 items representing how individuals can describe loneliness. This scale was designed to subjectively measure a person's feeling towards loneliness and being isolated from the social environment. After revision, UCLA Loneliness Scale version 3 is filtered into eight items (ULS-8) $(2,3,9,11,14,15,17,18)$ developed and revised by Hays and DiMatteo (1987).

The current study used ULS-8 with one additional item as used by Andangsari, Fitri, and Setyorini (2013) in their analysis on loneliness, subjective well-being and problematic Internet use (PIU) on teenagers who use social networking sites in Jakarta. One additional item was added due to the low reliability score of ULS-8, which increased to .73 after adding the item. In the current study, the reliability score was .602
(Cronbach's alpha). Items in ULS-8 were used without modifications with regards to Facebook use, because loneliness is a relatively permanent condition that does not easily change according to the situation faced by an individual. One example item is "How often do you feel lonely?" The response scale used is a Likert scale spanning from 1-4, with a higher score indicating higher agreement to the question statements.

Cognitive distortion was measured using Cognitive Distortion Scale (CDS) developed by Briere (2000). CDS consisted of 40 items divided into five dimensions: self criticism, self blame, helplessness, hopelessness, and preoccupation with danger. Self criticism is the tendency to criticize and devaluate someone, whether internally or towards other people. Self blame occurs on an unwanted event in someone's life. This includes blaming the self for unwanted events, even those outside of a person's own control. Helplessness is the perception that one cannot control important aspects in his/her own life. Hopelessness is a belief that the future is bleak and that one is fated to fail or suffer. Preoccupation with danger is the tendency to evaluate the world, especially the interpersonal world, as a dangerous place. The reliability score for CDS in the current study is .924 (Cronbach's alpha). Similar to ULS-8, items in CDS were used without modification related to the use of Facebook, again due to the idea that loneliness is a permanent, rather than a transient trait. One example item in CDS is "Easily losing hope." CDS uses a 1-5 Likert scale, with a higher number indicating higher agreement to the question statements.

\section{Results}

Description of subjects in the study will be explained through duration of Facebook use and activity in using Facebook. Descriptive and correlational data processes were done. Descriptive statistics were used to explain variables within the study, by categorizing subjects into high or low categories in loneliness and cognitive distortion variables. Correlational statistics were done using Spearman Correlation Rank to test the hypothesis of the current study.

\section{Descriptive Data}

In this study, scores on loneliness and cognitive distortion are categorized into two categories: "low" and "high", based on participants' scores. This categorization is based on the lowest and highest theoretical 
scores that the subject can get on both ULS-8 and CDS. A median split is done after obtaining the lowest and highest score.

The ULS- 8 consists of nine items with a scale of 1 to 4 , so theoretically subjects can acquire a score between 9 to 36. Following a median split, two total score categories were obtained: 9-22 for "low" and 23-36 for "high". The categorization was used to group subjects based on their ULS-8, and it was found that $59 \%$ of the subjects were categorized as having "high" scores in loneliness (see Table 1).

CDS, used to measure cognitive distortion in this study, had 40 items on a scale of 1 to 5 . Theoretically, subjects are able to acquire scores between 40 to 200 . Using a median split, the following score categories were found: scores of 40-120 were categorized as "low" scores, while 121-200 were categorized as "high". From the categorization, it was found that $67.2 \%$ of subjects scored "high" in cognitive distortion (see Table 2).

\section{Intervariable Correlation}

Results of a correlation analysis between the two main variables in the study showed a significant positive relationship between loneliness and cognitive distortion $(p<.005)$, where the correlation coefficient $(r=.271)$ is classified as low correlation (Sugiono, 2010). Based on the results, the hypothesis of the current study is accepted, and it can be concluded that there is a significant positive correlation between loneliness and cognitive distortion on teenage users of Facebook (see Table 3).

The significant positive relationship between loneliness and cognitive distortion is supported by the significant positive relationship between loneliness and each dimension of cognitive distortion (self criticism ( $r=.236, p<.005)$, self-blame $(r=.308, p<$ $.005)$, helplessness $(r=.244, p<.005)$, hopelessness $(r=.247, p<.005)$, and preoccupation with danger $(r=.234, p<.005))$. From the results, it can be seen that loneliness has the highest correlation with selfblame (see Table 4).

\section{Discussion}

The aim of the current study is to investigate the relationship between loneliness and cognitive distortion, and it was hypothesized that there is a significant positive relationship between loneliness and cognitive distortion on teenage users of Facebook. Supported by
Table 1

\begin{tabular}{ccc}
\multicolumn{2}{l}{ Level of Loneliness } \\
\hline Category & Score & Percentage \\
\hline Low & $9-22$ & $41 \%$ \\
High & $23-36$ & $59 \%$ \\
\hline
\end{tabular}

Note. Source: primary data

Table 2

Level of Cognitive Distortion

\begin{tabular}{ccc}
\hline Category & Score & Percentage \\
\hline Low & $40-120$ & $32.8 \%$ \\
High & $121-200$ & $67.2 \%$ \\
\hline Note. & Source: primary data &
\end{tabular}

Table 3

Loneliness and Cognitive Distortion

\begin{tabular}{|c|c|c|c|}
\hline \multirow[b]{2}{*}{$\begin{array}{c}\text { Loneliness } \\
\text { and }\end{array}$} & \multicolumn{2}{|c|}{ Spearman's rho } & \multirow[b]{2}{*}{$N$} \\
\hline & $\begin{array}{l}\text { Correlatior } \\
\text { Coefficien }\end{array}$ & $\begin{array}{c}\text { Sig. } \\
\text { (2-tailed) }\end{array}$ & \\
\hline Cognitive & 1 & & 146 \\
\hline distortion & $.271^{* *}$ & .001 & 146 \\
\hline
\end{tabular}

Table 4

Loneliness and Dimensions of Cognitive Distortion

\begin{tabular}{lcc}
\hline \multirow{2}{*}{$\begin{array}{c}\text { Cognitive Distortion } \\
\text { Dimension }\end{array}$} & \multicolumn{2}{c}{ Loneliness } \\
\cline { 2 - 3 } & Correlation & $\begin{array}{c}\text { Sig. } \\
\text { (2-tailed) }\end{array}$ \\
\hline Self Criticism & $.236^{* *}$ & .004 \\
Self Blame & $.308^{* *}$ & .000 \\
Helplessness & $.244^{* *}$ & .003 \\
Hopelessness & $.247^{* *}$ & .003 \\
Preoccupation with & $.234^{* *}$ & .003 \\
$\quad$ & & \\
\hline danger & &
\end{tabular}

the results of the study, the hypothesis was accepted. To further explain the results, the positive relationship between the two variables will be discussed through several aspects.

Loneliness is seen as a subjectively experienced unwanted emotional condition, related to the perception that the need for social satisfaction and intimacy was not satisfied. Loneliness involves a cognitive awareness of a deficiency of interpersonal and social relationship, leading affective reactions such as sadness, emptiness, and longing (Al Khatib, 2012). Cognitive distortion is thinking error related to how one interprets a situation (HuanHuan \& Su, 2013). It can be seen how loneliness and cognitive distortion occur due to cognitive factors, regarding how to perceive and interpret a situation.

Individuals with cognitive distortion have a negative or pessimistic view of the self, world, and future. 
$\mathrm{He} /$ she judges him/her-self to be incapable and believes that others feel the same way about him/her (Nyarko \& Amissah, 2014). Similarly, lonely individuals will have a negative self-evaluation related to his/her social skills. Loneliness is usually related with low self-esteem. It was even stated that the relationship between loneliness and self-esteem is stable throughout time ( $\mathrm{Al}$ Khatib, 2012).

Related to Facebook use, a significant relationship between loneliness and cognitive distortion occurs because when subjects are lonely, they also experience thinking errors related to Facebook. On the other hand, when subjects have thinking errors related to Facebook, they will feel lonely. Subjects who feel lonely because they did not get the desired response from others in Facebook will blame themselves for failing. Lonely individuals will live in guilt, feeling helpless in their relationship with others in their social environment (Izgar, 2009). When subjects blame themselves because they don't spend time to access Facebook to update them with new information, they will be lonely due to feelings of social isolation. These assumptions, however, need to be supported with interviews on subjects with high scores of loneliness and cognitive distortion.

Motivation in using Facebook can influence teenagers' loneliness and cognitive distortion. There are two motivations in using communication technology such as the Internet, which are socio-affective regulation (SAR) and goods and information acquisition (GIA) (Hu, 2007). The first motivation is oriented on social or affiliation in Internet usage, whereas the second one is oriented on utility or practicality. SAR motivation shows negative effects on psychological well-being, such as loneliness and depression, due to the decrease of involvement in the social environment. Internet usage motivated by GIA shows positive effect by increasing social integration. The most frequent Facebook activity done by subjects were updating status, either only updating status $(21 \%)$ or including uploading pictures $(16.9 \%)$ as well. Seen from such activities, the motivation of subjects were more SARoriented, however this needs to be further investigated considering that the current study did not specifically identify the motivation of subjects for using Facebook.

A low correlation coefficient $(r=.271)$ between loneliness and cognitive distortion may occur because in the current study it was not necessary for subjects to be lonely before they use Facebook. Individuals who are lonely and then use Facebook are assumed to be more vulnerable to cognitive distortion compared to those who are lonely after using Facebook. This is because lonely individuals who use Facebook will be even more lonely because they do not get any response from Facebook friends as they expected, and thus these individuals will experience even more thinking erros (cognitive distortions). It will be easier for the individual to self criticise, self blame, felt helpless and hopeless, and preoccupied with environmental danger.

In addition, the low correlation between loneliness and cognitive distortion on teenage users of Facebook can occur because when compared to cognitive distortion, depression has more correlation with loneliness. Loneliness is often associated with depression in the literature; prolonged loneliness was found to cause depression (Izgar, 2009), and loneliness is found to have strong associations with depressive symptoms (Cacioppo \& Hughes, 2006). Cognitive distortion itself is excessive irrational thinking that can cause many psychological problems, such as depression (Nyarko \& Amissah, 2014). Despite the role of cognitive distortion in the development and occurence of depression (Singh, Yadav, Singh, \& Dhiman, 2011), cognitive distortion is still considered only an indicator of depression. People with cognitive distortion may not necessarily experience depression. Therefore, it is assumed that the relationship of loneliness and depresssion is stronger than loneliness and cognitive distortion.

From the correlational analysis between loneliness and cognitive distortion dimension, it was found that the highest correlation was on self-blame. Self-blame is described by Briere (2000) as the tendency for individuals to blame him/her-self on events that occur outside of his/her ability or control. This is in line with other studies associating self blame and loneliness, where it was found that self blame is related to loneliness, especially Characterological Self Blame (CSB) (Tilghman-Osborne, 2007). CSB is maladaptive because it is a form of self-reflection that blames the individual and the character possessed by the individual. Negative social experience will make teenagers blame themselves or attribute failures to their own incompetence or lack of acknowledgment and acceptance from others. This will lead to social withdrawal, depression, and tendency to internalize problems (de Minzi \& Sacchi, 2004).

A greater number of subjects had high scores on loneliness $(59 \%)$ compared to subjects who had low scores $(41 \%)$. Such numbers support the idea that loneliness is often associated with teenage development stage, because in this stage acceptance and love are two major factors in forming self-identity.

Among other development stages, the teenage development stage is usually the first time an indivi- 
dual becomes very acquainted with loneliness (Rokach, 2000). It can be stated that teenagers are vulnerable to experiencing loneliness (Bekhet, Zauszniewski, \& Nakhla, 2008; Hu, Jin, Hu, \& He, 2013)

Loneliness in early teens and teenagers can occur due to lack of friendship, acceptance, and exchange of intimacy with friends and loved ones (Bekhet, Zauszniewski, \& Nakhla, 2008). This becomes relevant when subjects who use Facebook experience loneliness, because Facebook is a means to stay connected with and know further about other people (Tartari, 2014). When subjects feel like they don't get acceptance or outright rejected in friendly interactions in Facebook, they may experience loneliness.

The cause of loneliness on teenagers who use Facebook need to be investigated further. Loneliness can occur due to social and emotional isolation (Zarei, Heydari, \& Adli, 2013). On emotional isolation, loneliness occurs due to a lack of emotional attachment with other people, whereas social isolation creates loneliness due to a lack of participation in social networks and interaction. The two causes of loneliness can occur on teenagers who use Facebook. Emotional isolation can occur during Facebook use when teenagers only have superficial connections, such as responding or being responded to only due to formality. Social isolation occurs when there is no involvement in Facebook interactions or when they lack time to interact with others offline.

The high amount of subjects who experience loneliness can be because they might be new members of Facebook and have not been actively using the website. New users of social media websites such as Facebook are more likely to experience loneliness compared to existing users $(\mathrm{Hu}, 2007)$. This may occur because new users are still engaged in exploring and discovering the features provided by Facebook, therefore they access Facebook more frequently. Existing users, on the other hand, may be bored by the website and thus may spend less time accessing and being occupied with Facebook. However, how long users have been using Facebook for was not controlled in the study, and thus this assumption needs to be taken carefully.

From the categorization of cognitive distortion, it was found that a majority of subjects had high scores in cognitive distortion $(67.2 \%)$. This may be possible because in their cognitive development, teenagers are placed in the formal operational stage, enabling them to think about different possibilities and about their own as well as other people's thoughts (Galanaki, 2012). In this stage, egocentrism occurs in which teenagers tend to fail to distinguish between the object of other people's thoughts and their own thoughts. They fail to understand what others are thinking and their own mental preoccupation; they assume that others are obsessed with their behavior and appearance. This egocentrism is manifested in imagery audience and personal fable, and will increase their tendency of having distorted thoughts, considering that cognitive distortions are seen as negative, unrealistic belief and assumptions about the self, the world, and the future (Nyarko \& Amissah, 2014). Individuals with cognitive distortions will focus only on themselves, and on extreme cases will criticize and be aware of themselves. The tendency to put too much focus on the self can be seen on both egocentric individuals and those with cognitive distortions.

The current study is unique because it examines two variables together: loneliness and cognitive distortion. Not many studies have associated loneliness and cognitive distortion, and thus it is difficult to find a comparison study, especially in the context of Indonesia. The results of the current study can be used as a baseline for future studies in the area.

From the discussion it was indicared that loneliness and depression as well as cognitive distortion and depression both have a greater association compared to loneliness and cognitive distortion. Future research could be done by involving three variables simultaneously: loneliness, cognitive distortion, and depression. This would enable researchers to understand the role of loneliness and cognitive distortion on depression. Furthermore, a path analysis can be done to see the relationship of the three variables.

\section{Limitations and Suggestions}

One limitation of the current study is that the level of loneliness for each subject was not controlled, with each subject having different levels of loneliness. The lack of control may mean that the varying levels of subjects' loneliness were not accounted for. Such different characteristics may infuence the interpretation of the results, for example those with high initial level of loneliness may respond differently compared to those with low initial loneliness on the use of Facebook and their condition of cognitive distortion. While this may be useful in a correlational study, where the varying level of loneliness can indicate the presence of relationship with cognitive distortion, it will be harder to generalize the finding that lonely users of Facebook will experience cognitive distortions.

Motivation of Facebook users was indicated to have an influence on loneliness and cognitive distortion 
(Hu, 2007). The current study, however, did not account for motivation, and so future studies can be done to link the basic factors such as motivation with other variables indicated to be the consequence of Facebook use.

In the current study, it was not known how long each user has been using Facebook for, and thus the relationship between loneliness and length of Facebook use cannot be analyzed. If this was done, a more in-depth understanding of the relationship between Facebook use and loneliness can be achieved. Therefire, for future studies, subjects should be asked how long they have been using Facebook for.

Another limitation of the study is the uneven distribution of questionnaires in the Jabodetabek area, considering that they are only distributed in North Jakarta, East Jakarta, South Jakarta, and Depok. There is no data that can represent Central Jakarta, West Jakarta, Tangerang, Bogor, and Bekasi. This means that the results of the study cannot be generalized to the regions where the questionnaires were not distributed in. Future studies should aim to have a more even distribution to help with the generalization of the results in Jabodetabek area.

Lastly, the current study did not fully investigate the specific causes of loneliness and cognitive distortion. Knowledge on such things will allow a more comprehensive discussion on subjects with high loneliness and cognitive distortion, and the relationship between loneliness and cognitive distortion. Future studies should not only be done using quantitative analysis, but should also incorporate qualitative methods such as interviews to further enrich the study results.

\section{Conclusion}

From a study of 146 teenagers in some areas of Jakarta and Depok, a low correlation between loneliness and cognitive distortion was found. Despite the limited number of subjects, this research is important because it involves a phenomenon that is rapidly developing in Indonesia, which is the use of Facebook. The results of this study support previous research on the negative effects on Internet usage, especially Facebook. Although small, the correlation between loneliness and cognitive distortion is still important. Teenagers in their general development stages are prone to experiencing loneliness, and using Facebook can be one of the many ways to reduce loneliness. However, Facebook use can instead cause or increase loneliness. This becomes more problematic when the cognitive aspect of loneliness is associated with cogni- tive distortion, which in turn indicates theoccurrence of depression. Results of the study also found relatively high scores on subjects' loneliness and cognitive distortion. Thus, it is important to make some guidelines for using Facebook positively, such as for academic purposes. One can create a Facebook group to discuss study materials, moderated by teachers. Regardless, the most important thing that should be done by parents and teachers is to help teenagers to get involved in social activities and other offline, face to face interactions. Teenagers can be motivated to do extracurricular activities to help them explore their identity as well as interact with other people to enhance their social life.

\section{References}

Al Kathib, S. A. (2012). Exploring the relationship among loneliness, self esteem, self efficacy, and gender in United Arab Emirates college students. Europe's Journal of Psychology, 8(1), 159-181. DOI:10.5964/ejop.v8i1.301

Andangsari, E. W., Fitri, R. A., \& Setyorini, A. (2013). Analisis loneliness, subjective well-being dan problematic Internet use (PIU) pada remaja pengguna jejaring sosial di Jakarta (Unpublished manuscript). Universitas Bina Nusantara, Jakarta.

Aydin, G. S., Muyan, M., \& Demir, A. (2013). The investigation of Facebook usage purposes, shyness and loneliness. Procedia-Social and Behavioral Sciences, 93, 737-741.

Bekhet, A. K., Zauszniewski, J. A., Nakhla, W. E. (2008). Loneliness: A concept analysis. Nursing Forum, 43(4), 207-213.

Briere, J. (2000). Cognitive distortion scale. Los Angeles: Psychological Assessment Resources.

Cacioppo, J. T., \& Hughes, M. E. (2006). Loneliness as specific factor for depressive symptoms: Cross sectional and longitudinal analysis. Psychology and Aging, 21(1), 140-151.

de Minzi, M. C. R., \& Sacchi, C. (2004). Adolescent loneliness assessment. Adolescence, 39(156), 701709.

Dhaha, I. S. (2013). Predictors of Facebook addiction among youth: A structural equation modeling (SEM). Journal of Social Sciences, 2(4), 186-195.

Dogruer, N., Menevis, I., \& Eyyam, R. (2011). What is the motivation for using Facebook? Procedia Social and Behavioral Science, 15, 2642-2646.

Galanaki, E. P. (2012). The imaginary audience and the personal fable: A test of Elkind's theory of 
adolescent egocentrism. Scientific Research, 3(6), 457-466.

Gierveld, J. J., Tilburg, T., \& Dykstra, P. A. (2006). The Cambridge handbook of personal relationship: Loneliness and social Isolation. Cambridge: Cambridge University Pers.

Hays, R. D., \& DiMatteo, M. R. (1987). A short form measure of loneliness. Journal of Personality Assessment, 51(1), 69-81.

HuanHuan-Li., \& Su-Wang. (2013). The role of cognitive distortion in online game addiction among Chinese adolescence. Children and Youth Services Review, 35, 1468-1475.

$\mathrm{Hu}-\mathrm{Mu}$. (2007). Social use of the Internet and loneliness (Unpublished dissertation). The Ohio State University.

Hu,Y., Jin. Y., Hu, C., \& He, H. (2013). Loneliness and their relationship to explicit and implicit self esteem. Scientific Research, 4(5), 455-458.

Izgar, H. (2009). An investigation of depression and loneliness among school principals. Educational Sciences: Theory \& Practice, 9(1), 247-258.

Kok, J. K., Lee, W. Y., \& Chong, S. L. (August 2015). Facebook community and disclosure behaviours. International Journal of Social Science and Humanity, 5(8), 691-694. DOI:10.7763/ IJSSH. 2015.V5.541

Kuss, D. J., \& Griffiths, M. D. (2011). Excessive online social networking: Can adolescents become addicted to Facebook? Education and Health, 29(4), 68-71.

Lee, B. W,. \& Stapinski, L. A. (2013). Seeking safety on the Internet: Relationship between social anxiety and problematic Internet use. Journal of Anxiety Disorders, 26(1), 197-205.

Leung, L. (2002). Loneliness, self disclosure, and ICQ (I Seek You) use. Cyber Psychology \& Behavior, 5(3), 241-251.

Naeemi, S., Tamam, E., Hassan, S., \& Bolong, J. (2014). Facebook usage and its association with psychological well being among Malaysian adolescents. Procedia-Social \& Behavioral Sciences, 155, 87-91.

Nyarko, K., \& Amissah, C. M. (2014). Cognitive distortion and depression among undergraduate students. Research on Humanities and Social Sciences, 4(4), 69-75.

Oguz, E., \& Cakir, O. (2014). Relationship between levels of loneliness and Internet addiction. Anthrophologist, 18(1), 183-189.
Omolayo, B. O., Balogun, S. K., \& Omole, O. C. (2013). Influence of exposure to Facebook on self esteem. European Scientific Journal, 9(11), 148-159.

Peplau, L. A., \& Perlman, D. (1981). Toward a social psychology of loneliness. In R. Gillmour, \& S. Duck (Eds), Personal relationships 3: Personal relationship in disorder (pp. 31-56). London: Academic Press.

Rokach, A. (2000). Causes of loneliness in adolescence: Cross cultural study. Journal of Adolescence and Youth, 8, 65-80.

Rosa, G. A. M., \& Santos, B. R. Januari (2014). Who I am on Facebook ? Usage and motivation through user eye. Psychology Research, 4(1), 60-73.

Seepersad, S. (2004). Coping with loneliness: Adolescent online and offline behavior. Journal Cyber Psychology \& Behavior, 7(1), 35-39.

Singh, N., Yadav, R., Singh, G., \& Dhiman, C. (2011). Adolescent depression in relation to cognitive distortion and parental bonding. Journal of Mental Health and Human Behaviour, 16(2), 79-86.

Sugiono (2010). Metode penelitian kuantitatif \& RND. Bandung: Alfabeta

Tartari, E. (2014). Facebook use through mobile devices by teenagers in Albania. Journal of Educational and Social Research, 4(4), 88-91.

Tilghman-Osborne, C. (2007). The relation of guilt, shame, behavioral self-blame, and characterological self-blame to depression in adolescents over time (Unpublished thesis). Vanderbilt University, Tennessee.

Wedding, D. (Summer 2000). Cognitive distortion in the poetry of Anne Sexton. Suicide and Life Threatening Behavior, 30(2), 140-144.

Yang, C.C, \& Brown, B. B. (2013). Motives for using Facebook, patterns of Facebook activities, and late adolescents' social adjusment to college. Journal Youth Adolescence, 42, 403-416.

Zarei, E., Heydari, H., \& Adli, M. (2013). The relationship between loneliness and social acceptance and the academic performance of students. Journal of Life Science and Biomedicine, 3(2), 171-175.

Zaremohzzabieh, Z., Samah, B. A., Omar, S. Z., Bolong, J., Kamarudin, N. A. (2014). Addictive facebook use among university students. Asian Social Science, 10(6), 107-116.

Zuckerberg, si pembuat Facebook (2009). Tekno Kompas. Retrieved from http://tekno.kompas.com/ $\mathrm{read} / 2009 / 02 / 28 / 1243001 /$ zuckerberg.si.pembuat.fa cebook. 